\title{
Evaluation of Personnel Information System Performance at the Department of Population and Civil Registration of Bengkayang Regency Using Cobit 5
}

\author{
Tania Linda, Agustinus Fritz Wijaya ${ }^{2}$ \\ Information System, Fakultas Teknologi Informasi, Satya Wacana Christian University, Indonesia \\ Email:1682017414@student.uksw.edu, 2agustinus.wijaya@uksw.edu
}

\begin{abstract}
Information system is a combination of each unit managed by people, hardware (hardware), software (software), computer networks, and data communication networks (communications), and databases (databases) that collect, transform, and disseminate information. about the form of organization. The purpose of research at the Department of Population and Civil Registry of Bengkayang Regency is to record population administration data which includes data covering birth data, marriage data, and death data, identity cards, family cards, and child identity cards. COBIT version 5 framework method to review the management of the Personnel Information System at the Department of Population and Civil Registration of Bengkayang Regency. The domain used in COBIT 5 is "Monitoring, Evaluation and Assessment" (MEA). The research methodology is a qualitative descriptive method with service observations, collecting data and informal interviews. The results of this study determine the maturity level of the Bengkayang Regent's Population and Civil Registry and provide recommendations for the application of information technology to be better in the future.
\end{abstract}

Keywords: Evaluate the performance of Information System, COBIT 5, Domain MEA

\section{PENDAHULUAN}

Evaluasi kinerja SI pada sebuah pemerintahan ini sangatlah penting dalam mencapai tujuan pada pemerintah agar biasa mencari tahu hasil dari kinerja sistem informasi dalam pencatatan data kedudukan pada masyarakat. Pengembangan teknologi informasi pada pemerintahan sangatlah membantu kinerja pada sistem informasi dalam meningkatkan kinerja dan daya saing untuk melaksanakan kegiatan dan pelayanan kebutuhan pemerintahan. Penilaian kinerja merupakan penentuan secara periodik efektivitas operasional suatu organisasi berdasarkan sasaran, standar, dan kriteria yang telah ditetapkan sebelumnya. Sistem informasi merupakan seperangkat komponen yang saling berhubungan dan berfungsi mengumpulkan, memproses, menyimpan dan mendistribusikan informasi untuk mendukung pembuatan keputusan dan pengawasan dalam 
organisasi[1].Jadi penilaian kinerja sistem informasi adalah suatu cara untuk menentukan efektivitas sebuah sistem informasi sebuah organisasi dimana sistem informasi memiliki fungsi untuk mendukung pengambilan keputusan dan pengawasan.

Penilaian kinerja dilakukan untuk mendorong keberhasilan[2]. Control Objective for Informasi and Related Technology (COBIT 5) merupakan generasi terbaru pada bantuan ISACA dibuat berdasarkan pengalaman penggunaan COBIT. Dalam menggunakan COBIT 5 pada Evaluasi Kinerja Sistem Informasi Kepegawaian Dinas Kependudukan dan Catatan Sipil untuk menciptakan nilai yang optimal dari IT dengan menjaga keseimbangan antara mewujudkan manfaat dan mengoptimalkan tingkat resiko dan penggunaan sumber daya. COBIT 5 menggunakan praktik tata kelola dan manajemen untuk menjelaskan tindakan Praktik yang baik untuk efek tata kelola dan manajemen lebih perusahan IT. Domain Monitor, Evaluate and Assess (MEA) akan digunakan sebagai alat ukur evaluasi karena domain ini menekan pada pengawasan dan evaluasi secara menyeluruh terhadap sistem informasi[3]. Dengan adanya domain pengawasan untuk mempermudah memberikan evaluasi terhadap keadaan sistem informasi pada dinas kependudukan dan catatan sipil kabupaten bengkayang serta juga memberikan rekomendasi untuk dapat digunakan perbaikan pengolahan sistem informasi.

Dinas Kependudukan dan Pencatatan Sipil Kabupaten Bengkayang yang memliliki fungsi dan tujuan memberikan layanan kepada kelompok masyarakat dengan menjalankan peran sebagai organisasi , dalam pemenuhan kebutuhan masyarakat. Dinas Kependudukan dan Catatan Sipil Kabupaten Bengkayang merupakan lembaga yang bertujuan untuk pencatatan data administrasi kependudukan yang meliputi data yang mencakup tentang data kelahiran, data perkawinan, dan data kematian, kartu tanda penduduk, kartu keluarga, dan kartu identitas anak. Kantor Pelayanan Dukcapil merupakan salah satu dinas yang melayani masyarakat khususnya dalam pengelolaan kependudukan. Penelitian ini bertujuan untuk mengacu pada framework COBIT versi 5 untuk mereview pengelolaan SI Kepegawaian pada Dinas Kependudukan dan Catatan Sipil Kabupaten Bengkayang Domain yang digunakan dalam COBIT 5 adalah "Monitoring, Evaluasi dan Penilaian" (MEA). Hasil penelitian mengetahui kematangan Kependudukan dan Catatan Sipil Bupati Bengkayang, serta memberikan saran-saran untuk penerapan teknologi informasi agar lebih baik kedepannya.

\section{METODE}

Metode penelitian ini menggunakan metode deskriptif kualitatif adalah salah satu dari jenis penelitian yang termasuk dalam jenis penelitian kualitatif. Adapun tujuan dari penelitian ini adalah untuk pengamatan keadaan yang terjadi saat penelitian berlangsung. Penelitian ini dilakukan dengan pengamatan kondisi sistem absensi pengawai dinas kependudukan dan pencatatan sipil kabupaten 
Vol. 1, No. 2, June 2021

p-ISSN: 2656-5935 http://journal-isi.org/index.php/isi

e-ISSN: $2656-4882$

bengkayang. Pada penelitian ini menggunakan proses Domain yaitu Domain MEA (Monitor, Evaluate and Assess) yang berfokus pada proses penilaian Disdukcapil dalam sistem kebutuhan yang sedang berjalan masih memenuhi atau tidak. Penelitian terdapat beberapa tahapan yaitu:

1. Studi Literatur, Pada tahap pertama proses kajian terdahulu yang relevan sebagai landasan penelitian mempelajari pustaka yang mengenai COBIT Framework, tahapan evaluasi kinerja sistem informasi.

2. Pengumpulan Data, tahap kedua melakukan pengumpulan data dengan cara observasi dan wawancara di Dinas Kependudukan dan Catatan Sipil Kabupaten bengkayang. Melakukan wawancara dengan Para narasumber yang sesuai dengan bidang mereka yang dipandang memiliki keterkaitan langsung dengan bagian pelayanan dan kearsipan di Dinas Kependudukan dan Catatan Sipil Kabupaten Bengkayang.

3. Analisa Data, tahap ketiga melakukan analisis dan wawancara terhadap sistem informasi mengacu pada data yang menggunakan framework COBIT 5 dengan Domain MEA.

4. Rekomendasi dan Kesimpulan, pada tahap keempat langkah terakhir ini memberikan rekomendasi serta kesimpulan mengenai analisis data dan memberikan saran. Tahap ini juga proses pembuatan laporan hasil dengan Domain MEA (Domain Monitor, Evaluate and Assess) dari kerangka kerja COBIT 5 dan kesimpulan penelitian.

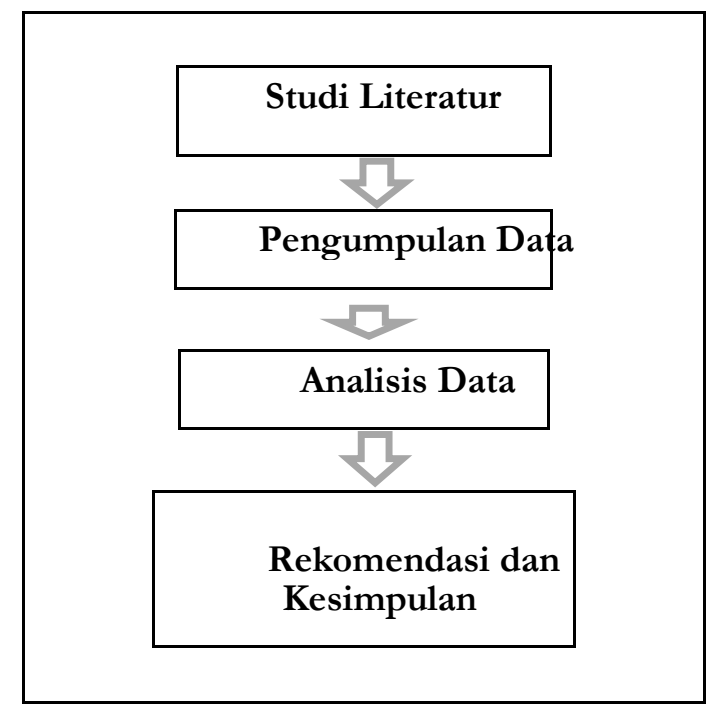

Gambar 1. Diagram Alir Penelitian 
Tahapan penelitian pada Gambar 1 dapat dijelaskan sebagai berikut:

1. Tahapan Pertama, mempelajari Pustaka/sumber literatur mengenai COBIT Framework, tahapan evaluasi kinerja sistem informasi .

2. Tahapan Kedua, melakukan proses pengumpukan data yang dilakukan dengan langkah-langkah seperti observasi dan wawancara, yang di laksanakan ke Dinas Kependudukan dan Pencatatan Sipil Kabupaten Bengkayang dan menentukan narasumber yang sesuai dengan bidangnya dalam melakukan wawancara dengan para narasumber. Alasan pemilihan narasumber adalah mereka yang dipandang memiliki keterkaitan langusng pada bagian pelayanan di Disdukcapil Bengkayang.

3. Tahapan Ketiga, melakukan analisis data dan wawancara terhadap sistem informasi yang mengacu pada COBIT Framework yang menghasilkan Domain MEA (Domain Monitor Evaluate and Assess). Pada tahap ini dilakukan setelah pengumpulan data yang sudah valid di analisis yang berhubungan dengan hasil COBIT.

4. Tahap Kempat, Langkah terakhir memberikan rekomendasi yang dapat digunakan untuk perbaikan atau pengembangan sistem kedepannya, dan kesimpulan penulis berdasarkan hasil analisis data yang kemudian menghasilkan rekomendasi yang diberikan kepada Disdukcapil Bengkayang sebagai acuan perbaikan maupun pengembangan sistem kedepannya.

\subsection{Tinjauan Pustaka}

Zelafehad Mega Naskay dan Agustinus Fritz Wijaya mengenai Evaluasi Kinerja Sistem Informasi Kepegawaian pada Dinas Kependudukan dan Catatan Sipil Salatiga Menggunakan COBIT 5 bertujuan untuk Domain MEA (Monitor, Evaluate and Assess) akan digunakan sebagai alat ukur evaluasi karena domain ini menekan pada pengawasan dan evaluasi secara menyeluruh terhadap sistem informasi. membantu meningkatkan kinerja dalam sebuah organisasi sistem informasi untuk menjamin kinerja agar lebih efektif dan efisien dalam mencapai tujuannya, penelitian ini juga untuk meningkatkan kematangan teknologi informasi pada Dinas Kependudukan dan catatan sipil [4].

Penelitian menurut Vinieta Zhafarina, Sasono Wibowo dalam menggunakan framework COBIT versi 5 dengan penelitian menggunakan domain MEA (Monitor, Evaluate, and Assess) untuk pemantauan dan evaluasi tata kelola EGovernment Badan Kepegawaian Daerah Kota Semarang. Terkait masalah yang ada dibutuhkan proses pemantauan yang konsisten pada sistem tata kelola EGovernment supaya masalah yang ada dapat diperbaiki dengan baik. Dengan digunakannya COBIT versi 5 domain MEA (Monitor, Evaluate, and Assess) sebagai acuan yang berfokus pada proses pengawasan bagaimana sebuah TI 
dikelola pada organisasi apakah sudah mematuhi penilaian yang independen berkaitan dengan efektivitas sistem IT [5].

Christine Juliane, Rakhmayudhi, dan Nuraeni mengenai "Pengukuran Kinerja Sistem Informasi di PT.Rancek sukses Bandung dengan menggunakan framework COBIT 5.0" penelitian bertujuan untuk mengukur kinerja SIOS (Sistem Informasi Kios) karena sering menimbulkan biaya tagihan yang tidak wajar dan data yang dihasilkan tidak akurat. Dari hasil penelitian disimpulkan nilai Capability process bahwa penggunaan SIOS mencapai level 0,03 (dibulatkan menjadi 0) artinya dari sistem informasi SIOS belum cukup bahkan jauh dari yang diperkirakan [4].

Penelitian menurut (Maria \& Haryani 2011) menggunakan COBIT framework 4.1, menilai sejauh mana tingkat kematangan UKSW sudah menerapkan teknologi informasi dalam mendukung proses bisnis. Hasil dari penelitian tersebut dapat menghasilkan rekomendasi bagaimana cara tata kelola teknologi informasi yang harus ditingkatkan dalam berdasarkan pada kerangka COBIT, dan menyimpulkan bahwa teknologi informasi di UKSW telah dikelola dengan baik, di mana proses teknologi informasi untuk mendukung tujuan bisnis telah distandarkan, didokumentasikan dan dikomunikasikan dengan baik. Maria merekomendasikan dalam meningkatkan kinerja UKSW untuk di masa depan maka evaluasi teknologi informasi harus tetap dilakukan dan kualitas layanan teknologi informasi lebih ditingkatkan hari demi hari [4].

Berdasarkan tinjauan pustaka diatas para penulis menyimpulkan menggunakan Framework COBIT 5 merupakan proses yang lebih efektif untuk melakukan kegiatan evaluasi pada suatu organisasi terhadap tata kelola teknologi informasi pada berbagai bidang yang mengimplementasikan teknologi informasi pada suatu bisnis. Kinerja merupakan konstruk multifaceted dimana masing-masing pihak yang berkepentingan terhadap kinerja cenderung mendefinisikan kinerja sesuai dengan pemahaman dan kepentingannya. Demikian juga kinerja sering dianggap sebagai konstruk multidimensi yang tidak hanya dikaitkan dengan keseluruhan organisasi tetapi juga dengan bagian-bagian dalam organisasi termasuk unit aktivitas, proses dan individu karyawan. Karena itulah sangat tidak mengherankan jika kinerja didefinisikan secara beragam[6]. Kinerja oleh Suyadi Prawirosentono diartikan sebagai hasil kerja yang dapat dicapai oleh seseorang atau sekelompok orang dalam suatu organisasi, sesuai dengan wewenang dan tanggung jawab masing-masing, dalam rangka upaya mencapai tujuan organisasi bersangkutan secara legal, tidak melanggar hukum dan sesuai dengan moral maupun etika Prawirosentono [7].

Menurut Stufflebeam dalam Lababa, evaluasi adalah "the process of delineating, obtaining, and providing useful information for judging decision alternatives," Artinya evaluasi merupakan proses menggambarkan, memperoleh, dan 
menyajikan informasi yang berguna untuk merumuskan suatu alternatif keputusan. Masih dalam Lababa, Worthen dan Sanders mendefinisikan "evaluasi sebagai usaha mencari sesuatu yang berharga (worth) [8]. COBIT (Control Objectives for Information and Related Technology) merupakan audit sistem informasi dan dasar pengendalian yang dibuat oleh Information Systems Audit and Control Association (ISACA) dan IT Governance Institute (ITGI). COBIT 5 yang merupakan Framework yang membantu perusahan dalam mencapai sebuah kerangka dimana untuk menciptakan nilai yang optimal dalam mengelola tata kelola teknologi informasi, dengan memberikan kerangka kerja dan kontrol yang akan diterapkan secara internasional pada perusahaan untuk mencapai tujuan dengan menjaga keseimbangan manfaat dan mengoptimalkan resiko serta sumber daya [6]. Berikut terdapat 3 proses Cobit 5 antara lain sebagai berikut:

1. MEA01 Pengawasan, Evaluasi dan Penilaian Kinerja, dan Kesesuaian (Monitor, Evaluate and Assess Performance, And Conformance)

2. MEA02 Pengawasan, Evaluasi, dan Penilaian Sistem dari Kontrol Internal (Monitor, MEA03 Pengawasan, Evaluasi, dan Penilaian Sistem Kebutuhan Eksternal (Monitor, Evaluate, and Assess the System of Internal) [9].

Tingkat Kapabilitas Proses berdasarkan pada ISO/IEC 15504 mengenai Software Engineering dan Process Assessment. Pada COBIT 5 terdapat enam tingkat antara lain:

1. Level 0, Incomplete Process, Proses tidak diimplementasikan atau gagal untuk mencapai tujuan prosesnya. Pada level ini tidak ada bukti dari setiap pencapaian sistematis tujuan proses.

2. Level 1, Performed Process, Proses diimplementasikan mencapai tujuan prosesnya.

3. Level 2, Managed Process, Proses yang dilakukan sekarang diimplementasikan dengan cara dikelola (direncanakan, dimonitor, dan disesuaikan) dan produk kerjanya secara tepat ditetapkan, dikontrol, dan dipelihara.

4. Level 3, Established Process, Proses yang dikelola sekarang diimplementasikan menggunakan proses definisi yang mana mampu mencapai hasil prosesnya.

5. Level 4, Predictable Process, Proses yang didirikan sekarang beroperasi dalam batas-batas yang didefinisikan untuk mencapai hasil prosesnya.

6. Level 5, Optimizing Process, Proses diprediksi yang terus ditingkatkan untuk memenuhi arus yang relevan dan tujuan bisnis proyek[10].

\section{HASIL DAN PEMBAHASAN}


Dinas Kependudukan dan Catatan Sipil merupakan lembaga yang bertujuan untuk pencatatan data administrasi kependudukan yang meliputi data yang mencakup tentang data kelahiran, data perkawinan,dan data kematian, kartu tanda penduduk,kartu keluarga, dan kartu identitas anak. Dinas Dukcapil merupakan salah satu dinas pelayanan untuk melayani masyarakat khususnya dalam mengurus administrasi kependudukan. Penilaian Kinerja dilakukan dengan SKP (Sasaran Kinerja Pegawai). Dilakukan setiap 1 tahun sekali, dan setiap akhir tahun dikumpulkan pada pimpinan.SKP adalah komponen dalam menilai prestasi kerja pegawai sesuai dengan Peraturan Pemerintah No 46 Tahun 2011 tentang Penilaian Prestasi Kerja Pegawai Negeri Sipil. Tujuan umum organisasi memberikan pelayanan untuk membuat kedudukan pada masyarakat dalam dokumen kependudukan.

Pada tahap ini mengukur tingkat kematangan pada Disdukcapil Bengkayang berdasarkan hasil observasi, wawancara di setiap bagian yang terkait menggunakan COBIT 5 dengan menggunakan satuan domain yaitu domain Monitor Evaluate and Assess (MEA). Dimana domain terdiri 3 kontrol objektif yang berfokus pada proses penilaian kebutuhan organisasi dan sistem yang sedang berjalan masih memenuhi atau tidak, serta monitoring berkaitan dengan penilaian independen efektivitas sistem serta kemampuan untuk memenuhi penilaian. Kondisi saat ini Disdukcapil Bengkayang dilakukan dengan proses wawancara mengenai proses MEA framework COBIT 5 dengan narasumber Disdukcapil Bengkayang ditentukan berdasarkan posisi, jabatan dan tanggung jawab yang berkaitan dengan proses MEA untuk aplikasi SKP ( Sasaran Kinerja Pegawai).

\section{MEA01 (Memonitor, Mengevaluasi dan Menilai Kinerja dan Kesesuaian)}

Evaluasi pengawasan dilakukan mencangkup kesesuaian informasi yang dihasilkan dengan kesesuaian kondisi yang ada di Dinas Kependudukan dan Catatan Sipil Kabupaten Bengkayang. Dalam penilaian kinerja memiliki aplikasi SKP (Sasaran Kinerja Pegawai) yang dapat mengolah data, proses pengumpulan data dilakukan dengan absensi setiap dinas diantaranya Dinas Kependudukan dan Catatan Sipil Kabupaten Bengkayang yang harus dilaporkan sebagai acuan pembagian insentif para pegawai. Proses pengawasan juga dilakukan dengan cara koreksi informasi yang ada di beberapa data untuk diberikan keterangan pada karyawan yang melakukan tugas di luar dinas.

\section{MEA02 (Memantau, Mengevaluasi Menilai sistem Pengendalian internal)}

Mengevaluasi pengendalian internal dalam penggunaan sistem informasi pada Dinas Kependudukan dan Catatan Sipil Kabupaten Bengkayang absensi lah yang lebih efektif untuk mengendalikan proses bisnis dan menertibkan jam masuk atau 
Vol. 1, No. 2, June 2021

p-ISSN: 2656-5935

http://journal-isi.org/index.php/isi

e-ISSN: $2656-4882$

jam keluar para karyawan. Pada kegiatan monitoring, evaluasi dan penilaian sistem kendali internal setiap pegawai harus menerapkan evaluasi kinerja pegawai yang berkaitan dengan pengoperasian sistem informasinya, dengan cara monitoring dan evaluasi kinerja para pegawai akan lebih mudah dilibatkan pada staf ahli bidang teknologi informasi yang berkaitan dengan kegiatan audit kinerja staf pengelola sistem informasi.

3. MEA03 (Monitor, mengevaluasi menilai kepatuhan dengan persyaratan eksternal)

Mengoperasikan komputer atau skill pegawai menjadi salah satu syarat untuk mengendalikan sistem, pelaksanaan kelancaran menjadi jaminan untuk menjalani pengawasan serta mengontrol sistem sesuai standar yang telah diberikan dalam kebijakan menjalankan tugas, Kegiatan pengawasan menjadi kepatuhan eksternal dalam membantu pendataan kependudukan dan catatan sipil pada Disdukcapil. Kegiatan pengawasan sesuai dengan kebijakan organisasi, standar dan prosedur yang diberikan. Berdasarkan hasil observasi dan pengamatan terkait tingkat kematangan domain MEA (Monitor, Evaluate, and Assess) kinerja sistem informasi pada Disdukcapil Bengkayang, yaitu memenuhi kriteria level 2 atau Managed process dikarenakan sistem SKP (Sasaran Kinerja Pegawai) ini sudah diterapkan namun belum bisa dikembangkan lebih lanjut. Rekomendasi atau Target untuk kedepannya adalah level 3 atau Established Process agar bisa lebih baik kedepannya. Dapat dilihat pada spider chart dibawah ini.

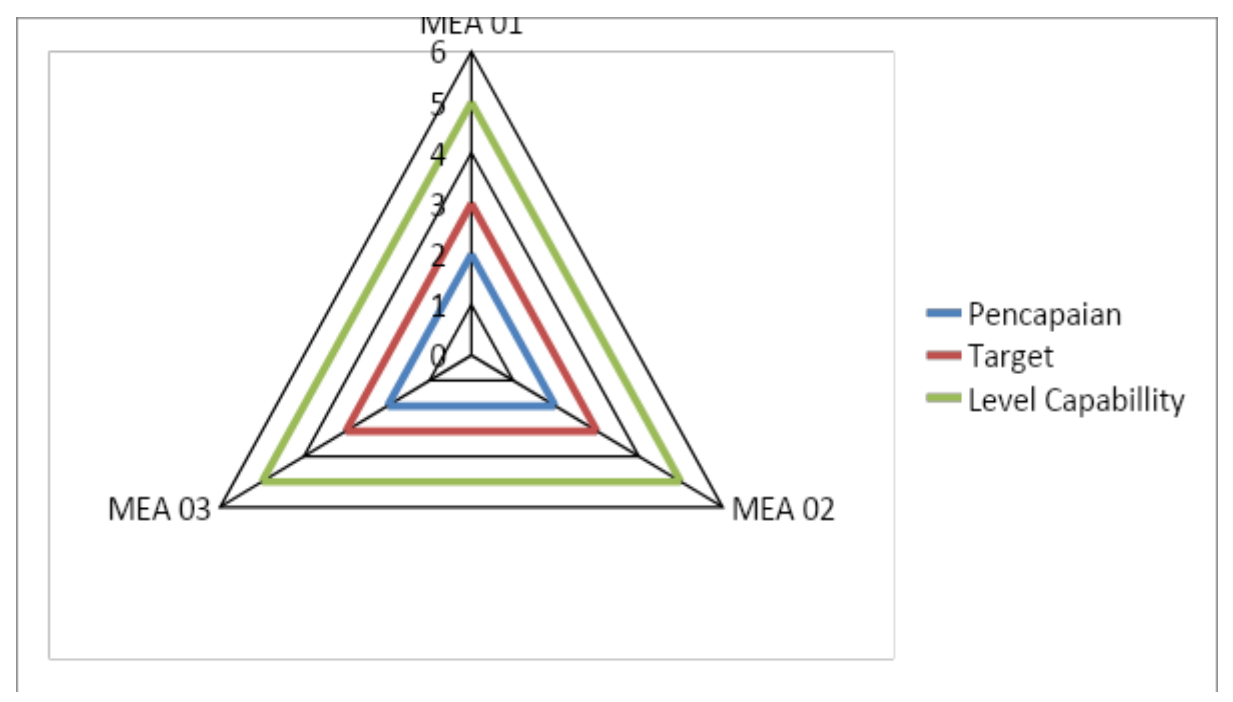

Gambar 2. Spider Chart Tingkat Kematangan 


\section{KESIMPULAN}

Berdasarkan penelitian dan pengamatan menggunakan COBIT 5 dapat disimpulkan bahwa dari penilaian kinerja sistem informasi Disdukcapil Bengkayang yang belum mencapai level 3 atau Established Process; dan Tingkat kematangan domain MEA (Monitor, Evaluate, and Assess) telah diimplementasikan yang memenuhi level 2 atau Managed Process dengan sesuai sistem yang sudah diterapkan, namun belum bisa dikembangkan lebih lanjut dan mengharuskan Disdukcapil bengkayang meningkatkan dalam pengoptimalilasi penggunaan SKP( Sasaran Kinerja Pegawai) agar bisa memberikan pencapaian yang terbaik terhadap tujuan organisasi.

\section{DAFTAR PUSTAKA}

[1] Jogiyanto, “Konsep Dasar Sistem Informasi," Konsep Dasar Sist. Inf.,2017.

[2] N. Nursam, "Manajemen Kinerja," Kelola J. Islam. Educ. Manag., 2017, doi: 10.24256/kelola.v2i2.438.

[3] Noorhasanah, W. W. Winarno, and D. Adhipta, "Evaluasi Tata Kelola Teknologi Informasi Berbasis Framework COBIT 5," Eval. TATA KELOLA Teknol. Inf. Berbas. Framew. COBIT 5 Semin. Nas. Teknol. Inf. Dan Multimed. 2015, 2015.

[4] Z. M. Naskay and A. F. Wijaya, "Evaluasi Kinerja Sistem Informasi Kepegawaian pada Dinas Kependudukan dan Catatan Sipil Salatiga Menggunakan COBIT 5," J. Bina Komput., vol. 2, no. 1, pp. 85-97, 2020, doi: 10.33557/binakomputer.v2i1.807.

[5] vinieta \& sasono wibowo Zhafarina, "Evaluasi Sistem E-Government Berdasarkan Cobit,” vol. 2, pp. 1-18, 2016.

[6] lili sari A. Purba and K. Harahap, "Kinerja Pelayanan Dinas Kendudukan dab Pencatatan Sipil Kepada Masyarakat,” J. Chem. Inf. Model., vol. 53, no. 9, pp. 1689-1699, 2019, doi: 10.1017/CBO9781107415324.004.

[7] M. Sapti, "KAJIAN TEORI KINERJA," Kemamp. Koneksi Mat. (Tinjauan Terbadap Pendekatan Pembelajaran Savi), vol. 53, no. 9, pp. 1689-1699, 2019.

[8] H. Herlina, S. Zauhar, and S. Suryadi, "Kinerja Dinas Kependudukan Dan Catatan Sipil Dalam Pelayanan Administrasi Kependudukan Di Kabupaten Kotabaru Kalimantan Selatan," J. Ilmu Sos. dan Ilmu Polit. Univ. Tribhuwana Tunggadewi, vol. 4, no. 3, p. 42444, 2015.

[9] ISACA, COBIT 5 Framework. 2012.

[10] R. Samo, "Audit Control Capability Level Tata Kelola Sistem Informasi Menggunakan COBIT 5 (Studi: Direktorat TIK UPI Bandung)," J. Inf., 2015. 